В. О. Гороховатський ${ }^{1}$, С. В. Гадецька ${ }^{2}$, Р. П. Пономаренко ${ }^{1}$

${ }^{1}$ Харківський національний університет радіоелектроніки, Харків, Україна

${ }^{2}$ Харківський національний автомобільно-дорожній університет, Харків, Україна

\title{
ЛОГІЧНИЙ АНАЛІЗ ТА ОБРОБЛЕННЯ ДАНИХ ЗАДЛЯ КЛАСИФІКАЦІЇ ЗОБРАЖЕНЬ НА ПІДСТАВІ ФОРМУВАННЯ СТАТИСТИЧНОГО ЦЕНТРУ ОПИСУ
}

\begin{abstract}
Предметом досліджень $є$ моделі для класифікації зображень у просторі описів як множини дескрипторів ключових точок при розпізнаванні візуальних об'єктів у системах комп'ютерного зору. Метою $є$ розвинення структурного методу класифікації шляхом впровадження логічного оброблення даних із використанням ймовірнісного розподілу у вигляді статистичного центру. Завдання: розроблення математичних та програмних моделей для обчислення релевантності описів зображень із використанням логічного аналізу, вивчення властивостей, варіантів застосування, значень параметрів моделей, оцінювання результативності за наслідками оброблення експериментальної бази зображень. Застосовуваними методами $є$ : детектор BRISK для формування дескрипторів ключових точок, інтелектуальний аналіз даних, математична статистика, засоби визначення релевантності для множин даних, програмне моделювання. Отримані результати: ефективність способу класифікації на основі логічного аналізу з використанням статистичних центрів залежить від відстаней між центрами еталонів бази. Застосування логічного аналізу спрощує оброблення і підвищує швидкодію класифікації. Найкращі результати щодо класифікації окремих дескрипторів показав підхід 3 використанням уточнених центрів. Використання концентрованої частки даних опису дає можливість ретельніше зосередитися на його відмінностях з іншими описами. Висновки. Наукова новизна - удосконалення методу класифікації зображень на основі впровадження логічного аналізу на підставі статистичного центру опису, що дає можливість модифікувати склад опису зі збереженням властивостей об' єктів в аспекті результативної класифікації. Практична значущість роботи полягає у досягненні прийнятого рівня ефективності класифікації за визначеною моделлю релевантності, підтвердженні працездатності запропонованих модифікацій оброблення даних на прикладах зображень, розробленні програмних моделей для впровадження описаних методів класифікації у системах комп'ютерного зору.

Ключов і слов а : структурні методи класифікації зображень, ключова точка, детектор BRISK, дескриптор, статистичний центр, концентрований опис, логічний аналіз, релевантність описів, результативність класифікації, аг-
\end{abstract} регований образ.

\section{Вступ}

Суть технологій інформаційного пошуку у системах комп'ютерного зору полягає у аналізі, ідентифікації, відборі та відображенні візуальних даних відповідно до інформації визначеного запиту. Основний критерій результативності при цьому - стабільне забезпечення об'єктивного оцінювання релевантності виявлених візуальних даних стосовно системи фіксованих еталонних образів [1-8]. Багатовимірна природа візуальної інформації часто не дає можливості її безпосередньо аналізувати чи класифікувати, що викликає необхідність розроблення спрощених підходів на підставі розбиття даних на блоки чи компоненти $[2,3,9]$. У структурних методах розпізнавання візуальних об'єктів за описом у вигляді множини ключових точок (КТ) багатовимірність даних визначається як розміром окремого дескриптора зображення (вектор до 512 компонентів), так і кількістю КТ у описі (100-500). Тому підходи щодо спрощення оброблення даних опису шляхом їх проектування або розбиття на фрагменти суттєво зменшують обчислювальні витрати [10].

Продуктивною ідеєю $є$ подання даних опису кластерною моделлю, що скорочує обчислення у сотні разів [11]. Ідеальним варіантом для результативної класифікації є випадок, коли візуальний об’єкт у просторі значень його дескрипторів може бути поданий єдиним кластером, хоча більш реальною все-таки вважаємо модель подання множини дескрипторів кількома (3...5) кластерами [12]. Важливим критері$\epsilon м$ при цьому $є$ забезпечення валідності даних, тобто відповідності використаної моделі даних результати- вному вирішенню прикладної задачі [13]. У відомих методах класифікації на базі структурного опису зображення, за виключенням традиційного підходу голосування КТ типу «множина-множина», вивчається два основних підходи: шляхом обчислення відстані у просторі інтегрованих ознак для опису $[14,15]$, а також безпосередня класифікація окремих дескрипторів до класу на підставі деякого «центру опису» $[10,11]$. По-елементний аналіз опису розпізнаваного об'єкту на предмет еквівалентності його елементів 3 образом зразку є менш вимогливим до дії завад на зображенні, але потребує більш досконалого аналізу.

Метою статті $\epsilon$ розвинення структурного методу класифікації зображень шляхом впровадження логічного оброблення даних із використанням ймовірнісного розподілу у вигляді статистичного центру для опису як множини дескрипторів.

Задачами дослідження $є$ розроблення математичних та програмних моделей задля обчислення релевантності описів зображень із використанням логічного аналізу, вивчення властивостей, варіацій застосування, значень параметрів моделей, оцінювання результативності за наслідками оброблення експериментальної бази зображень.

\section{1. Побудова простору ознак}

Нехай $B^{n}$ - векторний простір, що містить вектори розмірності $n$ з бінарними значеннями, потужність множини $B^{n}$ дорівнює card $B^{n}=2^{n}$. Будемо ототожнювати простір $B^{n}$ із множиною дескрипторів - векторів, побудованих детектором ключових точок (КТ) зображення [14-16]. 
Розглянемо фіксовану скінченну підмножину $Z \subset B^{n}$ бінарних векторів, яку складає опис аналізованого зображення у вигляді набору дескрипторів KT. Загалом $Z$ можна вважати мультимножиною, так як ії̈ елементи можуть повторюватися або бути достатньо подібними між собою. Таке подання сприяє представленню візуального об'єкта як сукупності його структурних елементів, а значення кожного дескриптора $є$ результатом екстрагування значущих ознак окремих просторових фрагментів зображення. Предметно фіксовану множину $Z=\left\{\mathrm{z}_{v}\right\}_{v=1}^{s}, \mathrm{z}_{v} \in B^{n}$, складають $s$ дескрипторів КТ iз бінарними значеннями, наприклад, сформованих детекторами ORB, BRISK, AKAZE [16].

Для фіксованого значення $n$ і конкретної послідовності із $s$ дескрипторів КТ розглянемо $Z$ у структурованій формі бінарної матриці $D=\left\{\left\{\mathrm{d}_{i, j}\right\}_{i=1}^{s}\right\}_{j=1}^{n}$. Для спрощення вважаємо значення $s$ однаковим для всіх еталонів, скінченна сукупність яких загалом представляє розпізнавані класи зображень об'єктів [14, 15].

Припустимо, що для кожного структурного опису як множини дескрипторів КТ властиве компактне ії̈ розміщення навколо деякого центру у векторному просторі $B^{n}$. Розширимо можливості аналізу, допустивши належність шуканого центру до множини $R^{1 n}$ векторів розмірності $n$, область визначення компонентів яких складає значення відрізку $[0, \ldots, 1]$. Це дає можливість для наявних даних оцінити допустиму межу для відстані в межах околу визначеного центру і далі на підставі встановленого порогу для відстані від центру здійснити класифікацію довільного опису шляхом обчислення кількості його еквівалентних елементів та вказаного центру. Зрозуміло, що у аспекті багатокласової класифікації результативність такого способу природно залежить від того, наскільки визначені центри відрізняються між собою у застосованому просторі ознак. Будемо трактувати послідовність бітів кожного 3 дескрипторів $\mathrm{z}_{v}$, що $\epsilon$ рядком матриці $D$, як поодинокі відліки $n$ - вимірного дискретного сигналу. За описом $Z$ тепер побудуємо агрегований образ $h(Z)$ деякого «центру» даних у формі векторної моделі:

$$
h(Z)=\left(h_{1}, \ldots, h_{j}, \ldots, h_{n}\right), h_{j}=\sum_{i=1}^{s} d_{i, j},
$$

де $h_{j}$ - суми елементів $D$ за стовпцями.

Назвемо вектор $h(Z)$ статистичним центром (СЦ) опису і покладемо його в основу класифікації. Важливим для реалізації процедур розпізнавання за вектором $h(Z) \in$ те, що подання $h(Z)$ не залежить від порядку слідування дескрипторів $z_{v}$ у множині $Z$, тобто модель $h(Z)$ є інваріантною до перемішування дескрипторів у складі опису, що відповідає довільному розміщенню рядків у матриці $D$. Фактично вектор $h(Z)$ - це узагальнений образ візуального об'єкта у $n$ - мірному просторі $C^{n}$ векторів 3 цілими невід'ємними компонентами, так як
$h(Z) \in C^{n}, h_{j} \geq 0$. Діапазон значень $h_{j}$ як складових $h(Z)$ визначається безпосередньо процедурою обчислення та числом дескрипторів $s$, його можна вважати заданим: $h_{j} \in\{0,1, \ldots, s-1, s\}$. Наряду з поданням $h(Z)$ опису будемо також мати на увазі нормоване подання $h^{s}(Z)=\left(h_{1}^{s}, h_{2}^{s}, \ldots, h_{s}^{s}\right)$, де $h_{i}^{s}=h_{i} / s$, що отримане нормуванням значень $h_{i}$ на число дескрипторів $s$ опису, причому $h_{i}^{s} \in R^{1}, h_{i}^{s} \in[0,1]$, $R^{1}$ - простір дійсних чисел на відрізку $[0,1]$. Вектори $h$ та $h^{S}$ можна віднести до апостеріорних характеристик опису.

\section{2. Класифікація з використанням статистичного центру опису}

Поставимо завдання шляхом здійснення статистичного аналізу даних бінарної матриці $D$, що має сенс зразку, на підставі значень векторів $h$ чи $h^{S}$ установити логічну процедуру щодо визначення істинності запиту про приналежність довільного бінарного вектору $b \in B^{n}$ до заданого опису $Z$.

2.1. Класифікація за порогом для відстані до «центру» опису. На етапі попереднього оброблення даних обчислимо $q_{i}=\rho\left(h^{s}, z_{i}\right), i=\overline{1, s}$, де $\rho\left(h^{s}, z_{i}\right)-$ деяка відстань між вектором $h^{s}$ та окремим дескриптором $z_{i} \in Z$. Діапазон значень відстані $\rho\left(h^{s}, z_{i}\right)$ відомий, так як простір порівнюваних векторів визначений метрикою та значенням даних. Наприклад, для манхеттенської відстані $\rho\left(h^{s}, z_{i}\right)=\sum_{v=1}^{n}\left|h^{s}(v)-z_{i}(v)\right|$ його значення для такого типу даних належать відрізку $[0, n]$. Здійснимо ранжирування значень відстаней $q_{i}$ до виду $q_{1} \leq q_{2} \leq \ldots \leq q_{s}$, виберемо із відсортованої послідовності значення $q_{s / 2}$, що знаходиться в центрі ранжируваної вибірки.

Оберемо величину $\alpha=q_{s / 2}$ у якості порогу $\alpha$ для відстані $\rho\left(h^{s}, z_{i}\right)$ задля класифікації запиту як довільного вектору $b$ до множини $Z$. Такий вибір значення порогу $\alpha$ забезпечує еквівалентність у межах значення відстані $\alpha$ для більшості векторів заданого опису $Z$ і його інтегрованої характеристики $h(Z)$, тобто виконання умови $\rho\left(h^{s}, z_{i}\right) \leq \alpha$. Замість відстані $\rho$ у такому способі вибору порогу можна використовувати також одну із мір подібності, наприклад, скалярний добуток векторів $\gamma\left(h^{s}, z_{i}\right)=\sum_{v=1}^{n} h^{s}(v) z_{i}(v)$, діапазон значень яких теж повністю визначений.

Обчислення порогу $\alpha$ шляхом переміщення по відсортованій вибірці вліво чи вправо від середини дає можливість додаткової адаптації до даних та може сприяти надійнішій класифікації.

За виділеною граничною множиною дескрипторів визначимо уточнений центр $h^{s^{*}}$, який обчис- 
люється за формулою (1) шляхом додавання та подальшого усереднення значень тільки тих дескрипторів опису, для яких виконана умова $\rho\left(h^{s}, z_{i}\right) \leq \alpha$ :

$$
\begin{gathered}
h^{s^{*}}=\sum_{i=1}^{s} z_{i} \chi\left(z_{i}\right) / s^{*}, \\
\chi\left(z_{i}\right)= \begin{cases}1, & \rho\left(h^{s}, z_{i}\right) \leq \alpha, \\
0, & \rho\left(h^{s}, z_{i}\right)>\alpha,\end{cases}
\end{gathered}
$$

де $s^{*}$ - число дескрипторів, $\chi\left(z_{i}\right)$ - характеристична функція за результатом логічного аналізу.

Уточнений СЦ $h^{s^{*}}$ можна застосувати для класифікації дескрипторів довільного опису. Виділена концентрована частина даних опису у вигляді уточненого центру (2) дає можливість ретельніше виявити властивості зосередження його даних у аспекті відмінностей з іншими описами.

Схематично класифікацію за величиною порога $\alpha$ для двох класів у представимо на рис. 1. Бачимо, що елементи, які належать околу центру першого класу, можуть одночасно належати до другого класу, і навпаки. Обидві площі цих сегментів для аналізованих даних визначають обсяг помилкових рішень при класифікації. До обох цих підмножин помилкових рішень належить перетин околів центрів, заштрихований на рис. 1, він напряму вказує число їх спільних елементів. Чим більший перетин, тим гірше розрізняються множини елементів різних класів.

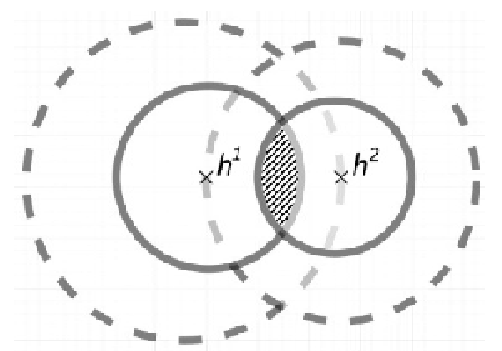

Рис. 1. Схема класифікації для двох класів: суцільна лінія - межа околу, пунктирна - межа класів

За вказаною схемою результат класифікації не $\epsilon$ симетричним: число елементів першого класу, помилково віднесене до другого, не дорівнює числу елементів другого класу, віднесених до першого. Зрозуміло, що зі зменшенням відстані між центрами кількість елементів 3 помилковою класифікацією зростає, так як збільшується площа перетину околів і площа, що визначає належність іншому класу.

Загалом класифікація 3 використанням СЦ для бази зображень може бути представлена такими етапами оброблення: 1) попередній аналіз кожного 3 описів еталонів бази задля визначення СЦ та порогу для класифікації дескрипторів за відстанню до нього; 2) аналіз множини дескрипторів об'єкта на предмет задоволення нерівності $\rho\left(h^{s}, z_{i}\right) \leq \alpha$ відносно кожного із еталонів; 3) підрахунок числа голосів дескрипторів, віднесених до кожного з еталонів; 4) визначення еталону $з$ найбільшою кількістю голосів.

2.2. Аналіз даних за структурою множини бітів. Застосуємо структурування даних, визначивши для кожного із бітів опису $Z$ (окремо чи для усіх бітів загалом) деякий поріг $\alpha_{b}$ для віднесення поодинокого біту вектора $b$ до цього опису шляхом встановлення граничного ступеня його близькості 3 відповідним значенням для компоненти векторів $h$ чи $h^{s}$. Цей поріг $\alpha_{b}$ можна обчислити на підставі квантилю для числових значень $h^{s}$ опису $Z$, виходячи із діапазону зміни його значень. Число дескрипторів опису, біти яких у межах квантилю еквівалентні відповідним бітам статистичного центру, можуть характеризувати міру «згуртованості» елементів опису навколо центру. Важливим показником також $€$ число бітів, які задовольняють умові еквівалентності. Поріг $\alpha_{b}$ можна вибрати так, щоб число еквівалентних бітів перевищувало половину від загального числа бітів. А класифікаційне правило для окремого дескриптора може бути засноване на умові перевищення числа еквівалентних бітів. Такою процедурою вибираються дескриптори, які за значенням звуженої кількості бітів є наближеними до СЦ. На їх підставі можна сформувати уточнений центр (2).

3 іншого боку, зважаючи на бінарний тип аналізованих даних, класифікаційне правило в обчислювальному аспекті може бути достатньо просто реалізовано як встановлення еквівалентності дискретизованого значення $h_{i}^{s}$ та біту $b_{i}$ : якщо біт $b_{i}=1$, в той же час $h_{i}^{s} \geq 0,5$, а також у випадку $b_{i}=0$ одночасно $3 h_{i}^{s}<0,5$ еквівалентність можна вважати визначеною. Загалом правило $\gamma\left(h_{i}^{s}, b_{i}\right)$ встановлення близькості $h_{i}^{s}$ та $b_{i}$ зводиться до перевірки істинності булевої функції виду

$$
\begin{gathered}
\gamma\left(h_{i}^{s}, b_{i}\right)=\operatorname{Pr}\left[\left(b_{i}=1\right) \&\left(h_{i}^{s} \geq 0,5\right) ;\right. \\
\left.\vee\left(b_{i}=0\right) \&\left(h_{i}^{s}<0,5\right)\right],
\end{gathered}
$$

що приймає значення 1 у випадку істинності предикату $P r$, що перевіряє виконання вказаних логічних умов. Ще простіше функція $\gamma\left(h_{i}^{S}, b_{i}\right)$ може бути побудована на підставі попередньої бінаризації значень $h_{i}^{s}$, що зводиться до обчислення логічної функції підрахунку кількості однакових бітів.

На підставі визначеного порогу для бітів чи задоволення логічного висновку класифікація довільного вектора $b \in B^{n}$ реалізується як підрахунок числа бітів, значення яких лежать у межах порогу чи відповідають логічній умові. Якщо число таких бітів більше $n / 2$, то вектор $b$ може бути віднесений до опису $Z$. Суть обох розглянутих способів полягає у побудові деякого околу точки - центра даних еталону у багатовимірному просторі з метою віднесення до нього всіх векторів, що знаходяться всередині околу. Перший спосіб визначає окіл на підставі значення відстані до центру, а другий - на підставі числа компонентів вектору, що належать околу. Другий спосіб встановлює більш жорсткі рамки для значень вектору даних. 
2.3. Класифікація за визначенням релевантності центрів описів. На підставі сформованих СЦ еталонних описів як векторів $h$ (чи $h^{S}$ ) їх релевантність 3 аналізованим описом довільного об'єкту також можна визначити безпосередньо за відстанню

$$
\rho\left(h^{1}, h^{2}\right)=\sum_{v=1}^{n}\left|h^{1}(v)-h^{2}(v)\right|,
$$

де $h^{1}, h^{2}$ - центри описів.

Зважаючи на апріорно відомі діапазони значень даних, за якими визначається $\rho\left(h^{1}, h^{2}\right)$, можна оцінити рівень значущості для релевантності задля реалізації класифікаційного рішення. Релевантність можна оцінити також за скалярним добутком СЦ описів

$$
\gamma\left(h^{1}, h^{2}\right)=\sum_{v=1}^{n} h^{1}(v) h^{2}(v)
$$

Чим більше значення (5) у межах [0, 512], тим більша подібність описів.

\section{Результати експериментальних досліджень}

Нами здійснено програмне моделювання запропонованих методів аналізу даних структурних описів мовою С\# у середовищі Visual Studio 2017 із використанням засобів бібліотеки Open CV [14, 15, 17]. Для проведення досліджень вибрані зображення (рис. 2), для яких обчислені структурні описи 3 використанням детектора BRISK (параметри $\mathrm{s}=176 ; \mathrm{n}=512$ ), околи КТ на рис. 1 зображені у вигляді невеликих кілець. Перші два зображення візуально досить схожі між собою («ангел та демон»), що завжди викликає труднощі при розпізнаванні навіть людським зором.

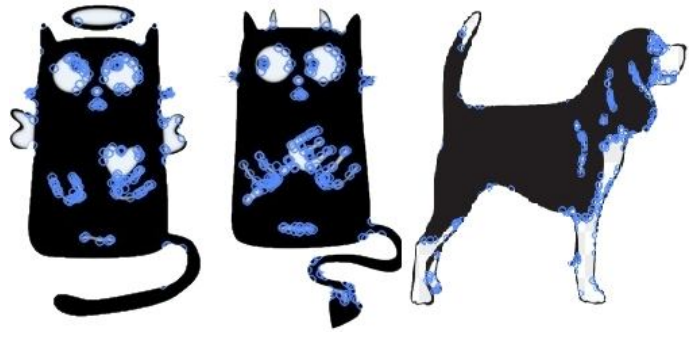

Рис. 2. Зображення з околами КТ

Обчислені манхеттенські відстані (4) між статистичними центрами h(i) (i - номер) зображень рис. 2 мають такі значення: $\rho(1,2)=23, \rho(1,3)=44$, $\rho(2,3)=37$, що загалом вказує на суттєву подібність між собою значень описів у досліджуваному просторі ознак СЦ, так як усі значення відстані у нашому прикладі лежать на інтервалі [0,512]. Відповідні нормовані значення складають $\rho^{*}(1,2)=0,044$, $\rho^{*}(1,3)=0,085, \rho^{*}(2,3)=0,072$. У той же час, як бачимо, навіть візуально схожі зображення 1 та $2 \epsilon$ можливість розрізняти за значенням (4). При обчисленні уточнених центрів (2) на підставі порогу для половини числа дескрипторів отримано:

$$
\rho^{*}(1,2)=0,052, \rho^{*}(1,3)=0,087, \rho^{*}(2,3)=0,076,
$$

тобто ступінь розрізнення між СЦ очевидно збільшилась. Це свідчить про певне покращення ефекти- вності класифікації. Отримана кількість числа голосів елементів еталонів, що віднесені до відповідного класу (рис. 2) шляхом порівняння їх відстані до уточненого центру з граничною, показана у табл. 1.

Таблиия 1 - Кількість класифікованих елементів опису еталонів

\begin{tabular}{|c|c|c|c|}
\hline Номер класу & $\mathbf{1}$ & $\mathbf{2}$ & $\mathbf{3}$ \\
\hline 1 & 44 & 29 & 11 \\
\hline 2 & 36 & 44 & 20 \\
\hline 3 & 32 & 27 & 44 \\
\hline
\end{tabular}

Як бачимо, значення числа голосів на діагоналі табл. 1 суттєво перевищують величини у рядку та стовпці, що підтверджує працездатність та результативність роботи методу при класифікації окремих дескрипторів. Схожі зображення 1 та 2, як бачимо, при цьому теж успішно розрізняються. Таким чином, формування концентрованої підмножини (кластеру) опису та уточненого СЦ (2) забезпечує хорошу результативність логічного оброблення.

Нами виконано обчислення відстаней між центрами для випадку, коли дескриптори розміром 512 подано у вигляді вектору 128 десяткових цілих чисел, де кожна компонента є значенням 4-х бітів дескриптора та приймає значення у діапазоні $0, \ldots, 15$. Максимальна відстань (3) для цього випадку складає $128 * 15=1920$. Отримані нормовані значення $\rho^{*}(1,2)=0,034, \quad \rho^{*}(1,3)=0,073, \quad \rho^{*}(2,3)=0,066$ вказують на те, що класифікаційні можливості при цьому не покращуються. Зауважимо, що результат застосування підрахунку голосів КТ відповідно до встановленої процедури залежить від порядку слідування аргументів, тобто не є комутативним (рис. 1). Тому, наприклад, при значенні порогу $\alpha(\mathrm{s} / 2)=\alpha(88)$ число КТ першого зображення при порівнянні з центром другого дорівнює 100, а число КТ другого зображення при зіставленні з центром першого - 70. Маємо, що візуально близькі зображення 1 та 2 методом класифікації окремих дескрипторів за встановленим порогом для відстані не класифікуються. У той же час решта пар зображень: 1-3, 2-3 розрізняються досить впевнено, так як кількість класифікованих КТ супротивних зображень для них лежить у межах 54...82, тобто менше 88. У той же час при використанні описів інших зображень (відстань між центрами із зображенням 1 складає 53) досягається впевнена класифікація.

Проведені дослідження у плані аналізу зниження та збільшення індексу граничного значення для кількості використаних дескрипторів відносно середини s/2. Конкретно із відсортованої послідовності були вибрані значення $\alpha(50)$ та $\alpha(120)$. Незважаючи на те, що при порозі $\alpha(50)$ спостерігалось деяке посилення розбіжностей для аналізованих описів, впевнена класифікація близьких зображень 1 та 2 при цьому також не забезпечена, при цьому інші зображення класифікуються.

Обчисленням за виразом (5) визначено величини скалярного добутку між центрами (максимум дорівнює 512): $\gamma(1,2)=120, \gamma(1,3)=119, \gamma(2,3)=118$. У той же час власні скалярні добутки (квадрати норм) 
для центрів $\gamma(1,1)=123, \gamma(2,2)=121, \gamma(3,3)=129$, що вказує на практичну відсутність потрібної властивості для функції скалярного добутку у плані розрізнення, так як нормований скалярний добуток $\gamma^{*}(1,2)=0,98, \gamma^{*}(1,3)=0,94$, тобто, значення скалярних добутків досить близькі між собою, що загалом не забезпечує класифікаційні можливості. На наш погляд, одним із факторів, що збільшує значення (5), $\epsilon$ бінарний вид аналізованих даних.

Загальний висновок $з$ експерименту полягає в тому, що застосування скалярного добутку замість манхеттенської відстані (4) дещо зменшує класифікаційні можливості граничної класифікації. У процесі моделювання також перевірялися можливості управління значенням порогу, що задає розміри околу для СЦ даних. Одним із варіантів було визначення єдиного порогу для бази класифікованих зображень, який обчислюється шляхом вибору мінімального серед порогів. Експерименти показали зменшення числа неправильно класифікованих КТ, але близькі зображення 1 та 2 при застосуванні такої модифікації не розрізняються. Іншим варіантом оброблення є вибір у якості центру того дескриптора із опису, який є найближчим за відстанню до СЦ. У цьому випадку центр $\epsilon$ елементом кластера [13]. Моделювання, як і передбачалось, засвідчило погіршення розрізненості зображень за рахунок «огрубіння» значення СЦ. Число неправильно класифікованих КТ збільшилось, хоча класифікація забезпечена, але близькі зображення також не розрізняються.

\section{Висновки}

Обговорюваний у статті спосіб класифікації зображень на підставі множин дескрипторів КТ грунтується на значеннях векторів - СЦ еталонних класів у сенсі середніх значень для дескрипторів їх опису. Цей спосіб досягає максимальної ефективності у ситуації, коли центри еталонів, що складають базу для розпізнавання, суттєво різняться. Застосування логічного аналізу спрощує оброблення і сприяє підвищенню швидкодії класифікації.

Найкращі результати щодо класифікації окремих дескрипторів показав підхід з використанням уточнених центрів. Виділення та використання концентрованої частки даних опису дає можливість точніше зосередитися на його властивостях, що відображають відмінності з іншими описами.

Наукову новизну дослідження складає удосконалення методу класифікації зображень на основі впровадження логічного аналізу інтегрованої інформації статистичного центру опису, що дає можливість модифікувати склад опису зі збереженням властивостей об'єктів в аспекті результативної класифікації.

Практична значущість роботи полягає у досягненні прийнятого рівня результативності класифікації за визначеною моделлю релевантності, підтвердженні працездатності запропонованих модифікацій оброблення даних на прикладах зображень, розробленні програмних моделей для впровадження описаних методів класифікації в системах комп'ютерного зору.

Побудова більш універсального підходу задля забезпечення гарантованої результативності для довільних даних може здійснюватися збільшенням числа центрів, комплект яких буде більш точно реалізувати апроксимацію даних для наявних еталонних описів. Обчислення набору таких центрів може здійснюватися, наприклад, через застосування систем ортогональних функцій або формуванням кластерів на множині аналізованих даних.

\section{СПИСОК ЛІТЕРАТУРИ}

1. Xu Zhang, Felix X. Yu, Svebor Karaman, Shih-Fu Chang (2017). Learning Discriminative and Transformation Covariant Local Feature Detectors. - The IEEE Conference on Computer Vision and Pattern Recognition (CVPR), pp. 6818-6826.

2. Masamichi KITAGAWA, Ikuko SHIMIZU (2019). Memory Saving Feature Descriptor Using Scale and Rotation Invariant Patches around the Feature Points. - IEICE Transactions on Information and Systems, Vol. E102.D, Issue 5, pp. 1106-1110.

3. Ravimal Bandara, Lochandaka Ranathunga, Nor Aniza Abdullah (2019). Nature Inspired Dimensional Reduction Technique for Fast and Invariant Visual Feature Extraction. - Int. Journal of Adv. Trends in Comp. Sc. \& Eng., Vol. 8, No.3, pp. 696-706.

4. Sivaram, M., Porkodi, V., Mohammed, A.S., Manikandan V. Detection of Accurate Facial Detection Using Hybrid Deep Convolutional Recurrent Neural Network. ICTACT Journal on Soft Computing. 2019. Vol. 09, Issue 02. pp. 1844-1850. DOI: 10.21917/ijsc.2019.0256

5. Amin Salih Mohammed, Saravana Balaji B., Hiwa Abdulkarim Mawlood. Conceptual analysis of Iris Recognition Systems. Advanced Information Systems. 2019. Vol. 3, No. 2. P. 86-90. DOI : https://doi.org/10.20998/2522-9052.2019.2.15

6. Svyrydov, A., Kuchuk, H., Tsiapa, O. (2018), "Improving efficienty of image recognition process: Approach and case study", Proceedings of 2018 IEEE 9th International Conference on Dependable Systems, Services and Technologies, DESSERT 2018, pp. 593-597, DOI: http://dx.doi.org/10.1109/DESSERT.2018.8409201

7. Худов В.Г. Аналіз відомих методів сегментування зображень, що отримані з бортових систем оптикоелектронного спостереження / В.Г. Худов, Г.А. Кучук, О.М. Маковейчук, А.В. Крижний // Системи обробки інформації, 2016. Вип. 9 (146). - С. 77-80.

8. Yaloveha V., Hlavcheva D., Podorozhniak A. Usage of convolutional neural network for multispectral image processing applied to the problem of detecting fire hazardous forest areas. Сучасні інформаційні системи. 2019. Т. 3, № 1. С. 116120. DOI: https://doi.org/10.20998/2522-9052.2019.1.19.

9. Баклицкий, В.К. Методы фильтрации сигналов в корреляционно-экстремальных системах навигации / В.К. Баклицкий, А.М. Бочкарев, М.П. Мусьяков. - М.: Радио и связь, 1986. - 216 с.

10. Gorokhovatskyi, V., Gadetska, S., Ponomarenko, R. (2019) Recognition of Visual Objects Based on Statistical Distributions for Blocks of Structural Description of Image. Lecture Notes in Computational Intelligence and Decision Making. - Proc. of the XV Int. Scientific Conf. "Intellectual Systems of Decision Making and Problems of Computational Intelligence" (ISDMCI' 2019), Ukraine, May 21-25, 2019, pp. 501-512. - Available online: https://rd.springer.com/chapter/10.1007/978-3-030-26474-1_35

11. Gorokhovatskyi, O. Analysis of Application of Cluster Descriptions in Space of Characteristic Image Features / O. Gorok- 
hovatskyi, V. Gorokhovatskyi, O.Peredrii // Data. - 2018, 3(4), 52. - doi: 10.3390/data3040052. Available online: https://www.mdpi.com/2306-5729/3/4/52

12. Lyashenko V., Kobylin O., Baranchykov Y. Ideology of Image Processing in Infocommunication Systems // 2018 Int. Scientific-Practical Conference Problems of Infocommunications. Science and Technology (PIC S\&T). - IEEE, 2018. - P. 47-50.

13. Миркин, Б. Г. Методы кластер-анализа для поддержки принятия решений: обзор. Препринт WP7/2011/03 / Б. Г. Миркин. - М.: Изд. дом НИУ ВШЭ, 2011. - 88 с.

14. Гороховатський В.О. Статистичні розподіли та ланцюжкове подання даних при визначенні релевантності структурних описів візуальних об'єктів / В.О. Гороховатський, С.В. Гадецька, Р.П. Пономаренко // Системи управління, навігації та зв’язку. -2018 . - №6 (52). - С. 87-92.

15. Гороховатський В.О. Вивчення статистичних властивостей моделі блочного подання для множини дескрипторів ключових точок зображень / В.О. Гороховатський , С.В. Гадецька, Н.І. Стяглик // Радіоелектроніка, інформатика, управління. -2019. - №2 . - С. 100-107.

16. Leutenegger, S., Chli, M., Siegwart, R. Y. (2011) BRISK: Binary Robust Invariant Scalable Keypoints. - Computer Vision (ICCV), pp. $2548-2555$.

17. OpenCV Open Source Computer Vision. [Електронний ресурс]. - Режим доступу: https://docs.opencv.org/master/index.html

Рецензент: д-р техн. наук, проф. Є. П. Путятін, Харківський національний університет радіоелектроніки, Харків Received (Надійшла) 10.07.2019 Accepted for publication (Прийнята до друку) 21.08.2019

\section{Логический анализ и обработка данных для классификации изображений на основе формирования статистического центра описания \\ В. А. Гороховатский, С. В. Гадецкая, Р. П. Пономаренко}

Предметом исследования являются модели для классификации изображений в пространстве описаний как множества дескрипторов ключевых точек при распознавании визуальных объектов в системах компьютерного зрения. Целью есть развитие структурного метода классификации путем внедрения логической обработки данных с использованием вероятностного распределения в виде статистического центра. Задачи: разработка математических и программных моделей для вычисления релевантности описаний изображений с использованием логического анализа, изучение свойств, вариантов применения, значений параметров моделей, оценивание результативности по результатам обработки экспериментальной базы изображений. Применяемые методы: детектор BRISK для формирования дескрипторов ключевых точек, интеллектуальный анализ данных, математическая статистика, способы определения релевантности для множеств данных, программное моделирование. Полученные результаты: эффективность способа классификации на основе логического анализа с использованием статистических центров зависит от расстояний между центрами эталонов базы. Применение логического анализа упрощает обработку и повышает быстродействие классификации. Наилучшие результаты классификации отдельных дескрипторов показал подход с использованием уточненных центров. Использование концентрированной части данных описания дает возможность более тщательно сосредоточиться на его отличиях от других описаний. Выводы. Научная новизна - усовершенствование метода классификации изображений на основе применения логического анализа с помощью статистического центра описания, что дает возможность модифицировать состав описания с сохранением свойств объектов в аспекте результативной классификации. Практическая значимость работы состоит в достижении приемлемого уровня эффективности классификации относительно определенной модели релевантности, подтверждении работоспособности предложенных модификаций обработки данных на примерах изображений, разработке программных моделей для применения описанных методов классификации в системах компьютерного зрения.

Ключевые слов а: структурные методы классификации изображений, ключевая точка, детектор BRISK, дескриптор, статистический центр, концентрированное описание, логический анализ, релевантность описаний, результативность классификации, агрегированный образ.

\section{Logical analysis and processing of data for the classification of images on the basis of formation of statistical center description \\ V. Gorokhovatskyi, S. Gadetska, R. Ponomarenko}

The subjects of research are the models for classifying images in the description space as multiple key point descriptors when recognizing visual objects in computer vision systems. The goal is to develop a structural method of classification by introducing logical data processing using probability distribution in the form of statistical center. The tasks include the development of mathematical and software models to calculate the relevance of image descriptions using logical analysis, study of properties, variations of application, values of model parameters, evaluation of the results of processing the experimental image database. The methods are used: a BRISK detector for forming the key point descriptors, data mining, mathematical statistics, means of determining relevance for data sets, software modeling. The following results were obtained. The effectiveness of a method of classification based on logical analysis using statistical centers that depend on the distances between centers of etalons. Logical analysis simplifies processing and increases classification speed. The best results on the classification of individual descriptors were shown by the use of refined centers. Using a concentrated portion of the description data allows you to focus more closely on its differences with other descriptions. Conclusions. The contribution of the paper is the improvement of the image classification based on the implementation of logical analysis of the statistical center description, which allows modifying the composition of the description while maintaining the properties of objects in terms of effective classification. The practical significance of the paper is the achievement of the accepted relevance level according to a defined model of relevance, to validate the proposed modifications to the processing of sample images, to develop software models for implementing the described methods of classification in computer vision.

Keywords: structural image recognition methods, key point, BRISK detector, descriptor, statistical center, concentrated description, logical analysis, relevance of descriptions, the effectiveness of classification, aggregated image. 